\title{
Chicks change their pecking behaviour towards stationary and mobile food sources over the first 12 weeks of life: Improvement and discontinuities
}

Chicks (Gallus gallus domesticus) learn to peck soon after hatching and then peck in rapid bursts or bouts with intervals of non-pecking activity. The food sources may be static such as seeds and chick crumb, or mobile such as a mealworm. Here, changes with age in pecking toward chick crumb and a mealworm were measured. Chicks were reared in pairs and their pecking of crumb food was video recorded in their pair housed environment, from food presentation, every third day from day 8 (wk2) to day 65 (wk10). Peck rate at crumb food reached maximum levels at day 32 (wk5), and then declined, fitting a quadratic model, with no sex, sex of cagemate, or box order effects. Within bouts the peck rate was higher and it increased to day 41 (wk6) and then declined, and here males pecked faster than females. A change in dietary protein concentration from $22 \%$ to $18 \%$ at day 28 (wk4) had no effect on subsequent peck rate. Pecking at and consumption of a mealworm in pair housed chicks were measured weekly from wks [5 to 12]. The latency to first worm peck and latency to swallow decreased to wk 8 and increased thereafter. The peck rate to first wormpeck and number of pecks to swallow increased to wk 8 and then declined paralleling the changes with crumb food. The increase in peck rate is coupled with an increase in efficiency in worm catching. The results are consistent with the view that the improvement in pecking ability and accuracy compliments change in nutritional requirement best served by an invertebrate food (IF) source requiring speed to achieve feeding success, especially with live prey. When this food source is no longer crucial these associated skill levels decline. An appreciation of the role of domestic fowl in controlling insect populations, at farm level, that are often vectors in disease spread is lacking. 
1 Chicks change their pecking behaviour towards stationary and mobile food sources over the first 12 weeks of life: Improvement and discontinuities

4 Kenneth J. Murphy a, b, c, ${ }^{*}$, Thomas J. Hayden ${ }^{\mathrm{a}}$ \& John P. Kent ${ }^{\mathrm{b}^{*}}$

5 a School of Biology and Environmental Science, University College Dublin, Belfield, Dublin 4, 6 Ireland.

$7 \quad{ }^{b}$ Ballyrichard House, Arklow, Co. Wicklow, Ireland.

$8{ }^{\mathrm{c}}$ is currently visiting researcher at Kings College London, Department of Forensic and Neurodevelopmental 9 Science, Institute of Psychiatry, London.

\section{Abstract}

11 Chicks (Gallus gallus domesticus) learn to peck soon after hatching and then peck in rapid bursts 12 or bouts with intervals of non-pecking activity. The food sources may be static such as seeds and 13 chick crumb, or mobile such as a mealworm. Here, changes with age in pecking toward chick 14 crumb and a mealworm were measured.

15 Chicks were reared in pairs and their pecking of crumb food was video recorded in their pair 16 housed environment, from food presentation, every third day from day 8 (wk2) to day 65 (wk10). 17 Peck rate at crumb food reached maximum levels at day 32 (wk5), and then declined, fitting a 18 quadratic model, with no sex, sex of cagemate, or box order effects. Within bouts the peck rate 19 was higher and it increased to day 41 (wk6) and then declined, and here males pecked faster than 20 females. A change in dietary protein concentration from $22 \%$ to $18 \%$ at day 28 (wk4) had no 21 effect on subsequent peck rate. 
22 Pecking at and consumption of a mealworm in pair housed chicks were measured weekly from 23 wks [5 to 12]. The latency to first worm peck and latency to swallow decreased to wk 8 and 24 increased thereafter. The peck rate to first wormpeck and number of pecks to swallow increased 25 to wk 8 and then declined paralleling the changes with crumb food. The increase in peck rate is 26 coupled with an increase in efficiency in worm catching.

27 The results are consistent with the view that the improvement in pecking ability and accuracy 28 compliments change in nutritional requirement best served by an invertebrate food (IF) source 29 requiring speed to achieve feeding success, especially with live prey. When this food source is no 30 longer crucial these associated skill levels decline. An appreciation of the role of domestic fowl in 31 controlling insect populations, at farm level, that are often vectors in disease spread is lacking.

32 *Corresponding Authors: Email: ken.murphy@kcl.ac.uk

\section{Introduction}


34 All five of the jungle fowl species are classified as highly omnivorous, eating a wide variety of

35 food items of plant and animal origin throughout the year with seeds often only a minor 36 component of the diet (Klasing, 2005). Food of animal origin that is frequently consumed include

37 termites, their eggs and pupae, winged ants, grasshoppers, spiders, moths, beetles and grubs 38 (Collias \& Collias 1967, Savory, 1989, Klasing 2005) with the breeding season in one study of 39 wild jungle fowl matching the annual cycle of termite availability (Collias \& Collias, 1967). The 40 nutritional needs of chicks change with age, requiring a higher protein diet, when young, for 41 growth and development, and lower levels for maintenance during adulthood, and this is reflected 42 in the changing dietary habits (Klasing, 1998). Gallinaceous and especially Gallus gallus young 43 consume high levels of invertebrate food (IF) during the first two months of life and levels 44 decline thereafter, regardless of insect availability (Savory, 1974; 1980, 1989, Savory et al., 45 1978). However, it should be pointed out following Savory (1989) that while the proportions of 46 IF decline with age in the growing chick the quantities consumed can continue to increase 47 especially within the first two months of life, and the increasing quantities will require more time 48 spent eating. This is important as insects provide protein and vitamin B12, essential for growth 49 that are almost non-existent in plant proteins (Klasing, 1998).

50 Domestic fowl adjust their nutritional intake depending on their physiological requirements 51 (Hughes, 1984). Broilers can self-select from different protein mixtures the appropriate 52 combination to maximise growth (Gous \& Swatson, 2000) and can adapt to diet changes within 5324 hours at all ages (Yo et al., 1998). Thus, chicks of different species can adjust their food intake 54 appropriate to nutrient requirements (Hale \& Green, 1988; Covasa \& Forbes, 1995; 55 Shariatmadari \& Forbes, 1993; Forbes \& Shariatmadari, 1994; Yo, et al., 1998, Klasing 1998). In 56 Sage Grouse (Centrocercus urophasianus) an increase in insects in the diet leads to increased 57 survival and growth (Johnson \& Boyce, 1990). 
58 In the feeding context recent studies have shown the considerable cognitive abilities of the chick 59 reflecting their phylogenetic and ecological history. For example, Rugani et al., (2014) show that 60 chicks are able to distinguish between numerical comparisons using training and test stimuli that 61 consisted of static 2D images with a number of black squares one of which was usually 62 associated with a hidden food reward. Chicks also have a leftward bias when locating a food 63 source after training to peck at either the fourth or sixth position in a series of 16 identical aligned 64 positions, when the training apparatus was rotated by 90 degrees (Rugani et al., 2010).

65 Chicks are pre-disposed to peck at small three-dimensional objects (Dawkins, 1968; Hogan, 66 1973). Pecking incorporates precisely coordinated, visual, neuromuscular and tactile processes, 67 that has been studied intensively in domestic chicks (Yo, et al., 1998, 1997b; Picard et al., 1997) 68 and hens (Hutchinson \& Taylor, 1962). Pecking involves the isthmo-optic visual system, which is 69 used to focus on moving prey and is better developed in ground feeding birds (Miles, 1972). The 70 relative myopia of the frontal fields adapts in the growing chick as the distance from ground to

71 beak changes (Hodos \& Erichson, 1990). During pecking the chick's head remains in a static 72 position for $75 \%$ of the time and two out of three pecks at wheat grain and pellets did not result in 73 feed intake (Yo et al., 1997), and thus a distinction between eating and pecking is made and these

74 pecks are assumed to be exploratory, and not included in their calculation of 'eating rate'. Here, 75 chicks are housed in pairs as feeding especially in younger birds takes place in a social context 76 involving mother hen in the first few days of life and thereafter siblings and/or conspecifics (for 77 review see Nicol, 2004).

78 At the behavioural level, discontinuities in development are recognised especially in play 79 behaviour (Bateson, 1981, Bateson \& Martin, 2013) and in social organisation of domestic fowl 
80 (Kent et al., 2009) and behaviours appropriate to a particular stage of development in young

81 chicks with the broody hen, can and do fall out of the behaviour repertoire when no longer

82 functional (Workman \& Andrew, 1989; Vallortigara et al., 1997). While much is known about

83 satisfying the dietary need of chicks in an agricultural production context little is known as to

84 how these needs are facilitated at a behavioural level. The concern here is with developmental

85 changes in the pecking behaviour of the chick with a static and a mobile food sources. Different

86 food sources may require different eating strategies.

87 We measured changes in pecking behaviour over the first 12 weeks of life in Brown Leghorn type

88 domestic chicks. Crumb food was used to study peck rate at static stimuli and mealworms were

89 used as the mobile food source. We hypothesised that rapid ballistic type pecking should develop

90 to facilitate capturing mobile IF that best meets the nutritional needs of the growing chick.

91 This research complies with the current laws of this country, and the ethical guidelines for the use

92 of animals in research as outlined by The Association for the Study of Animal Behaviour.

\section{Method}

94 Study 1 - Changes in peck rate toward a static food source (chick crumb) from day 8 to day 65.

95 The peck rate during the first minute from food crumb presentation from day 8 (wk2) to day 65

96 (wk10) and changes in the within bout peck rate in pair housed chicks were measured using video

97 recording and associated technology.

\section{Subjects and procedure}

99 Thirty-two (13 male and 19 female) incubator hatched domestic chicks (Brown Leghorn X) from 1004 batches with eight chicks per batch were randomly assigned to and reared in pairs in wooden 
101 boxes ( $49.3 \times 46.2 \times 35.6 \mathrm{~cm}$ high) with a wire mesh front and roof. The chicks in this study were

102 obtained from semi feral population of brown leghorn $\mathrm{X}$ hens with recent jungle fowl ancestry

103 and are thus genetically close to the original jungle fowl (see Rubin et al., 2010) and were

104 maintained in a flock of approx. 45 females with a fluctuating number of males from which the

105 eggs were obtained to produce chicks for this study. One pair (1 male and 1 female) was removed

106 due to developmental delay in one chick. Chicks were colour leg banded for identification. The

107 floor was covered with brown paper and straw and water was provided ad libitum. A crumb food

108 diet $(22 \%$ protein to day 28 , then $18 \%$ protein crumb diet - in accord with meal providers

109 recommendations for growing chicks) was provided in a $15.5 \mathrm{~cm}$ diameter dish. A window

110 provided natural illumination and in addition electric light (60 watt) was provided until $10 \mathrm{pm}$

111 each evening. In addition heat was provided with a 150 watt infrared electric light bulb over each

112 box as required, providing additional light.

113 For testing, food dishes were removed at 10pm, boxes cleaned and water replaced. Some, but

114 minimal food would have remained in the box environment. Next morning, from10am, chicks

115 were videorecorded (UC3000 8mm video camcorder) in their pair house environment, in a

116 random order, from food presentation, for twenty minutes. This procedure was repeated every

117 third day from day 8 to 65 . Videotapes were converted to media files (i.e. CDs) using Broadway

118 software, and analysed using the Observer Video Pro v4.0 behaviour analysis system (Noldus 119 Inc., 1993).

120 Peck rate during the first minute (+/- 5.12 sec) of feeding:

121 The peck rate during the first minute was measured by subtracting the latency to first peck (L)

122 from the duration (Mean=61.28 sec., Range=60.24-65.32, S.D. $=0.853$ ) to give the time spent

123 pecking $(\mathrm{T})$. The number of pecks $(\mathrm{P})$ was divided by the time (sec) spent pecking (T-L) to give a

124 peck rate per second and then multiplied by 60 , and expressed as pecks per minute (p/min.). 
125 Pecks / Min. = P/ (T(sec)-L) x60

126 Peck rate within bouts of pecking: To eliminate the effect of time spent in non-pecking activity

127 and give a more accurate measure of pecking capacity a within-bout peck rate was measured. The

128 first bout or series of 6-8 consecutive pecks occurring 30 seconds after the first peck was

129 identified. The time to first peck of this series (T1) was subtracted from time to the last peck

130 (T2), i.e. the duration of the bout. No inter-peck interval within the bout was more than half the

131 inter-bout interval on either side of the selected bout (see Machlis, 1977). The number of pecks

132 (P) was divided by duration (sec) of the bout (T2-T1), multiplied by 60 to give peck rate per

133 minute and was measured for days 11(wk2), 29(wk 5), 41(wk 6), 53(wk 8) and 65 (wk10).

134 Bout peck rate $/ \mathrm{min} .=\mathrm{P} /(\mathrm{T} 2-\mathrm{T} 1(\mathrm{sec})) \times 60$

\section{Statistics}

136 Repeated measures ANOVA in SAS v8.0 examined changes in peck rate over time, and within-

137 subjects contrasts and post hoc pairwise comparisons were calculated in SPSS v8.0 to determine

138 effects of batch, sex, sex of cagemate, and position of rearing box. Latency to peck and latency to

139 swallow were log transformed to normality, whereas number of pecks did not transform to

140 normal. Repeated measures ANOVA examined changes in the pecking behaviours

\section{Results}

142 Peck rate during first minute

143 The data is normal (Kolmogorov-Smirnov $\mathrm{Z}=0.733 ; \mathrm{p}=0.656$ ). Peck rate changed significantly

144 over the 10 weeks in all batches $(\mathrm{F}=20.25 ; \mathrm{df}=1,557 ; \mathrm{p}<0.001)$, rising gradually to day $32 / \mathrm{wk} 5$;

145 see Fig. 1, and Table 1). No sex $(p=0.248)$, sex of cage mate $(p=0.818)$, or box order effects were 
146 found $(\mathrm{p}=0.612)$. Batches 2 and 4 were hatched earlier in the season (mean day 171.5 days - mid

147 June) than batch 1 and 3 (mean day 262 - mid September) and peck rate peaked earlier ( 2 and 4 ,

148 mean 30.5days /wk5; 1 and 3, mean 42.5days/ wk7; $F=15.59 ; \mathrm{df}=3,23 ; \mathrm{p}<0.001$ ).

149 Bout peck rate

150 Within bout peck rate increased to day 41 (wk6) and then declined. The weeks differ significantly

$151(\mathrm{~F}=4.12 ; \mathrm{df}=1,113 ; \mathrm{p}<0.05)$ and the trend was also quadratic like that of the minute rate

$152\left(\mathrm{~F}=9.097 ; \mathrm{df}=1,16 ; \mathrm{p}<0.01 ; \mathrm{r}^{2}=0.7628\right)$, with no batch $(\mathrm{p}=0.211)$, cagemate $(\mathrm{p}=0.899)$, or box

153 order $(\mathrm{p}=0.697)$ effects, though males had a higher peck rate than females $(\mathrm{F}=4.52 ; \mathrm{df}=1,23$;

$154 \mathrm{p}=0.044)$ (see Table 2 and Fig. 2).

\section{Discussion}

156 Peck rate changes are significantly over the 10 weeks of the study for both total duration of 157 pecking which increased to day 32 (wk5), and then declined and within bout pecking which 158 increased to day $41(\mathrm{wk} 6)$ and then declined. It is the decline in peck rate that is the most 159 interesting and worthy of explanation and is considered below. Earlier hatched chicks (June) had 160 a peck rate peak at an earlier age and this is consistent with more rapid development rate in 161 chicks hatched early in the year and is attributed to the long days experienced early in the year in 162 the northern hemisphere accelerating development (Morris \& Fox, 1958). However both June 163 and September chicks show the same developmental trends. Within bout pecking was higher in 164 males and this may compensate for greater time spent in vigilance behaviour in male chicks 165 (Murphy, 2005). 
166 Study 2 - The effect of a change in dietary protein concentration on the peck rate of chick 167 crumb.

168 As the diet used in study 1 was changed from a $22 \%$ protein crumb diet to an $18 \%$ protein crumb 169 diet on day 28 (wk 4) it was necessary to control for the possible effects of this diet change on 170 subsequent behaviour. Thus the following experiment was carried out.

\section{Subjects and procedure}

17224 chicks from 2 batches of 12 ( $\mathrm{n}=10$ males; 14 females) were pairhoused as described in study 1

173 from day 8 (wk2) to 38 (wk 6). The diet of 6 pairs, three pairs from each of the two batches (Gp

174 A) were maintained on a $22 \%$ crumb to day 38 while the diet of Gp B was changed to an $18 \%$

175 protein crumb diet on day $28(\mathrm{wk} 4)$ as in experiment 1 . Peck rate was measured on the day before 176 the change (day 27) on the day after the change (day 29) and then at three-day intervals to day 38.

\section{Results}

178 Difference in peck rate between the two groups over the five test occasions $(\mathrm{F}=0.407, \mathrm{df}=4,88$, $179 \mathrm{p}=0.803)$, and between sexes $(\mathrm{F}=0.063, \mathrm{df}=1,20, \mathrm{p}=0.805)$ were not significant. A decline in 180 peck rate on the day following food change in the experimental $\mathrm{Gp} \mathrm{B}$, was found. There were no 181 significant difference between the two groups on the day before (day 27, Group A mean=100.9, $182 \mathrm{SD}=26.4$; Group B mean=108.3, $\mathrm{SD}=33.9 ; \mathrm{t}=-0.599, \mathrm{df}=22, \mathrm{p}=0.555)$ or on the day after the food 183 protein change (day 29, Mean group $\mathrm{A}=103.55, \mathrm{SD}=103.6$; Group $\mathrm{B}=$ mean=97.1, $\mathrm{sd}=22.0$, $184 \mathrm{t}=0.621, \mathrm{df}=22, \mathrm{p}=0.541)$.

185 Discussion

186 While changing the protein concentration of food from 22 to $18 \%$ protein was followed by a 187 slight drop in peck rate (Group B) this was not significant and there was no differences in the 
188 peck rate between the two groups either before or after food change. Thus the decline in peck

189 found in study 1 cannot be attributed to change in diet protein.

190 Study 3-Changes in peck behaviour towards a mobile food source, the mealworm (Tenebrio

191 molitor).

192 Here the concern is with changes in pecking behaviour, including latency to peck toward a living 193 and moving invertebrate - the mealworm - as the chick ages to wk12. The mealworm is similar to

194 if not the same as what chicks would encounter in natural settings.

195 Subjects

19610 incubator hatched chicks (4 hatched on 10 September ( $2 \mathrm{~m}$ and $2 \mathrm{f})$, and 6 hatched on 17 197 September (4f and $2 \mathrm{~m}$ )) were group-reared in their age groups to weeks five and four 198 respectively. They were colour leg banded and transferred randomly in pairs to the rearing boxes 199 described above, though in a large open shed. They could not see other chicks in the adjacent 200 boxes during rearing or testing. Natural lighting was provided and electrical light was made 201 available until $10 \mathrm{pm}$. They were fed ad libitum $22 \%$ crumb to day 28 , and from then $18 \%$ crumb 202 diet. Food dishes were removed at 10pm and on the following morning testing took place from $20310 \mathrm{am}$ in a random order.

\section{Procedure}

205 Chicks were each fed five mealworms on two consecutive evenings prior to each test. For testing 206 chicks were separated by a wire screen in the centre of their rearing boxes on the morning of the 207 test. Testing took place from week [5 to 12] at weekly (7 day) intervals. Two mealworms were 208 dropped from above, on to the floor of boxes simultaneously, one for each chick by an assistant 
209 seated behind the rearing boxes. When the mealworms were eaten and not less than 15 sec after

210 first presentation the procedure was repeated. If a chick did not eat the mealworm the procedure

211 was repeated $1 \mathrm{~min}$ after the previous presentation. The procedure was repeated three times on

212 each test day (i.e. three mealworms for each chick). Chicks were videorecorded and behaviour

213 measured from the presentation of the first mealworm. Videotapes are converted to media files

214 and analysed using the Observer 4.0 as described above. The following were measured; latency

215 from the mealworm landing onto the floor to the first wormpeck, latency to swallowing, number

216 of pecks to swallowing and peck rate to first wormpeck.

\section{Results}

218 Latency to peck, number of pecks to swallow and latency to swallow were not normally

219 distributed and were log transformed. Number of pecks did not transform to normal. Repeated 220 ANOVA and Friedman's nonparametric test with post hoc comparisons were used to examine 221 changes in the pecking behaviours toward the mealworm. One chick was removed from the study 222 as it swallowed only one mealworm during the first seven tests.

\section{Latency to first peck}

224 The latency to first peck differed significantly between weeks decreasing to wk 8 and then 225 increasing (see Table 3), reflecting increased efficiency to wk8 for catching live prey $(\mathrm{F}=3.208$, $226 \mathrm{df}=7,35, \mathrm{p}=0.01)$. Wk 5 differed from wk $8(\mathrm{p}=0.013)$ and $\mathrm{wk} 9(\mathrm{p}=0.041)$, and the overall trend

227 was quadratic $(\mathrm{F}=79.146, \mathrm{df}=1,5, \mathrm{p}<0.001)$. There were no sex differences $(\mathrm{F}=0.096, \mathrm{df}=1,52$, $228 \mathrm{p}=0.766)$.

229 Latency to swallow 
230 Latency to swallow changed between weeks decreasing to wk 8 and then increasing, reflecting

231 greater efficiency in catching live prey to wk $8(\mathrm{~F}=2.707, \mathrm{df}=7,35, \mathrm{p}=0.024)$. Wk 5 took longer

232 than wk $8(\mathrm{p}<0.05)$ and wk $9(\mathrm{p}=0.028)$ and the overall trend was quadratic $(\mathrm{F}=41.222, \mathrm{df}=1,5$ :

$233 \mathrm{p}=0.001$; see Table 3). There were no significant sex differences $(\mathrm{F}=0.307, \mathrm{df}=1,52, \mathrm{p}=0.597)$.

234 Number of pecks to swallow

235 The number of pecks to swallow did not differ between weeks $\left(\chi^{2}=12.027, \mathrm{df}=7, \mathrm{p}=0.1\right.$; see Table

236 3) and this may be due to the small number of pecks required to catch the mealworm, though

237 males took significantly fewer pecks to swallow $(\mathrm{F}=14.443, \mathrm{df}=1,52, \mathrm{p}=0.007)$.

\section{Discussion}

239 As chicks aged they became more efficient with a decrease in latency to peck and to swallow the

240 live prey to wk 8 and from wk 8 these latencies increased. Males took significantly fewer pecks

241 to swallow and this is consistent with a significantly greater within bout pecking rate at crumb

242 food (study 1) in males.

\section{General Discussion}

244 Chicks learn to peck soon after hatching and then peck in rapid bursts or bouts with intervals of

245 non-pecking activity (Machlis, 1977). Young chicks need a higher protein diet for growth and this

246 is reflected in dietary habits (Klasing 1998, 2005). We show that the chicks pecking rate for both

247 static and mobile food sources develops with age and reaches maximum peck rate levels at wk 5

248 for crumb food, with the within bout peak rate reaching maximum levels at wk 6 . For mealworms

249 the efficiency in terms of reduced latency to first peck and the reduced latency to swallow a

250 mealworm, improved to wk 8 and was coupled with an increase in the number of pecks to

251 swallow and an increase in the peck rate to wk8. After wk 8 there was a discontinuity of these 
252 efficiencies. These increases in peck rate to crumb food and to a mealworm show that the chicks 253 are getting more skilled and better prepared to capture the mobile IF with time.

254 The diet of young gallinaceous birds in the first two weeks of life and in Gallus gallus young in 255 the first two months of life contain a high proportion of IF (Savory et al., 1978, Savory, 1989, 256 Klasing 2005). From wks [1 to 4] between $50-90 \%$ of the diet in young Gallus gallus chicks in 257 naturalistic environments consists of IF and from wks [5-8] their diet was still between 10-50\% 258 IF (see Savory et al., 1978; Savory, 1989). It should be noted that as the birds grow, similar 259 proportions would mean greater quantities, and would require increasing efficiencies to maintain 260 the same or even a declining proportion of IF consumption.

261 Chicks can select the required dietary needs in a choice situation when offered different meal 262 diets with differing protein levels (Hughes, 1984; Kaufman et al., 1978; Gous \& Swatson, 2000; 263 Hale \& Green, 1988). In the natural situation IF is part of a variety of food types consumed by 264 this highly omnivorous species (Collias \& Collias, 1967, Savory, 1989; Klasing, 2005). High 265 protein IF are usually available during the reproduction season in most avian species (Klasing, 266 1998; Savory, Wood-Gush \& Duncan, 1978). In Northwest India, the main flights of termites are 267 in June/July, when young junglefowl chicks are plentiful (Collias \& Collias, 1967). In a feral 268 population the adult fowl diet from January to July consists mainly of grasses and seeds and from 269 August to December, mainly oats. By July, the diet of the chicks hatched in May consisted of 270 over 50\% IF. In autumn insects were less plentiful, and the diet of the growing feral chick was 271 very similar to that of the adult, though significantly, younger chicks continued to consume 272 higher levels of IF (Savory, Wood-Gush \& Duncan, 1978). 
273 It is important to note that the results of study 1 show that chicks hatched earlier in June did show

274 a peck rate during the first minute of food presentation earlier at wk 5 while September hatched

275 chicks showed a peak peck rate at wk 7 . However both groups showed the same pattern of

276 improvement to peak followed by a decline. The mealworm tested chicks that were also hatched

277 in September show their peak pecking levels at wk 8 followed by the discontinuity. Seasonal

278 factors have long been known to influence levels of growth and development in fowl (Morris \&

279 Fox, 1958) and more recently artificial light has been shown to advance the development of

280 seasonal avian reproductive physiology in an urban context in blackbirds (Dominoni et al., 2013).

281 Further, in imprinting studies the importance of drawing a distinction between developmental age

282 (age since incubation commenced) and chronological age (age since hatching) on performance

283 has long been appreciated (Gottlieb, 1961, 1963), and in a study of maternal behaviour the

284 necessity of drawing the same distinction when comparing twin born calves (shorter gestation)

285 with single born calves (longer gestation) has been noted (Kent, 1987). Season of birth does have

286 an effect on the course of development as seen here in study 1 with the early hatch chicks

287 showing a peak peck rate earlier. However, the developmental pattern with an increase in skill

288 levels up to a certain age and then followed by a decline, or rather a discontinuity, is robust across

289 the seasons. It should be pointed out that sharply timed behavioural changes in chicks and broody

290 hens over the first five weeks since hatching have been reported for other behaviours such as

291 ground scratching and dustbathing (Workman and Andrew 1989). They also showed that chicks

292 run ahead of the hen with particular behaviours increasing at a certain age, and then declining

293 sharply so that an explanation in terms of progressive maturation as part of development is

294 unlikely (Workman and Andrew 1989; Vallortigara et al., 1997). So the decline in peck rate found

295 here, after a period of progressive increase should not be seen as counter intuitive but rather as

296 part of normal development in the chicks. 
297 The findings here complement what is known about the changing nutritional needs and associated

298 behavioural habits of growing fowl in the natural and conventional environments. The changing

299 dietary needs for a high proportion of IF in growing chicks is facilitated at the behavioural level

300 by increased pecking efficiencies enabling the young chick to meet their then nutritional needs.

301 When a high IF diet is no longer necessary, the skill levels previously required decline.

302 Males had a higher within bout peck-rate when eating crumb than females. Males also took fewer 303 pecks to swallow a mealworm. Males engaged in more frequent and longer periods of vigilance 304 behaviour in this feeding context (Murphy, 2005). The role of vigilance during feeding behaviour 305 by male chicks may be best understood in a wider developmental and ecological context where 306 males-male and male-female inter-individual-distance increases especially during the 307 endogenous, testosterone driven juvenile phase wks 16-26 (Kent et al., 2009) and the role of 308 vigilance in this changing social context deserves further elaboration.

309 Further, in the omnivorous domestic fowl an appreciation of their role in controlling insect 310 populations, at farm level is lacking. Such insect populations are often vector in the spread of 311 disease (see Godfray, 2013) and fowl in the farmyard and in tropical and in sustainable bio-

312 diverse contexts (see Broom et al., 2013) may play an important and unappreciated role in their 313 control through their eating behaviour and dietary habits.

\section{Acknowledgements}

315 We would like to thank Dr. Finian Bannon for statistical assistance, Dr. Domhnall Jennings for 316 advice on using The Observer 4.0 and Mary Ann Kent for assistance with graphics. 


\section{References}

318 Bateson, P. (1981) discontinuities in development and changes in the organization of play in cats.

319 In: K. Immelmann, G.E. Barlow, L. Petrinovich \& M. Main (eds) Behavioural

320 Development: The Bielefeld Interdisciplinary Project. Cambridge University Press, UK

$321 \quad$ pp 281-295

322 Bateson, P. \& Martin P. (2013) Play Playfulness, Creativity and Innovation. Cambridge $323 \quad$ University Press, UK

324 Broom, D.M., Galindo, F.A. \& Murgueitio, E. (2013) Sustainable, efficient livestock production

325 with high biodiversity and good welfare. Proc. R. Soc. B. 280:20132025.

$326 \quad$ http://dx.doi.org/10.1098/rspb.2013.2025

327 Collias, N.E. \& Collias, E.C., 1967. A field study of the red junglefowl in Northeast India. $328 \quad$ Condor 69, 360-386.

329 Covasa, M., Forbes, J.M., 1995. Selection of foods by broiler chickens following corticosterone 330 administration. Brit. Poult. Sci. 36, 489-501.

331 Dawkins, R., 1968. The ontogeny of a pecking preference in domestic chicks. Z. Tierpsychol. 25, 170-186.

333 Dominoni, D., Quetting, M. \& Partecke, J., 2013. Artificial light at night advances avian 334 reproductive physiology. Proc. Roy. Soc. B 280: 20123017 $335 \quad$ http://dx.doi.org/10.1098/rspb.2012.3017

336 Forbes, J.M., Shariatmadari, F., 1994. Diet selection for protein by poultry. World Poult. Sci. J., 337 $50,7-24$

338 Godfray, H.J.C., 2013. Mosquito ecology and control of malaria. J. Anim. Ecology 82, 15-25. doi:10.1111/1365-2656.12003

340 Gottlieb, G., 1961. Developmental age as a baseline for determination of the critical period in imprinting. J. Comp. Physiol. Psychol., 54: 422-427. 
342 Gottlieb, G., 1963. Refrigerating eggs prior to incubation as a way of reducing errors in 343 calculating developmental age in imprinting experiments. Anim. Behav., 11, 290-292.

344 Gous, R.M., Swatson, H.K., 2000. Mixture experiments: a severe test of the ability of broiler 345 chicken to make the right choice. Brit. Poult. Sci. 41, 136-140.

346 Hale, C., Green, L. 1988. Effects of early ingestional experiences on the acquisition of 347 appropriate food selection by young chicks. Anim. Behav. 36, 211-224.

348 Hodos, W., Erichson, J.T., 1990. Lower field myopia in birds: an adaptation that keeps the ground 349 in focus. Vision Res. 30, 653-657.

350 Hogan, J.A., 1973. The development of food recognition in young chicks: I. Maturation and 351 Nutrition. J. Comp. Physiol. Psychol. 83, 355-366.

352 Hughes, B.O., 1984. The principles underlying choice feeding behaviour in fowls with special 353 reference to production experiments. World Poult. Sci. J. 40, 141-150.

354 Hutchinson, J.C.D., Taylor, W.W., 1962. Motor coordination of pecking fowls. Anim Behav 10, $355 \quad 55-64$.

356 Johnson, G.D., Boyce, M.S., 1990. Feeding trials with insects in the diet of Sage Grouse chicks. 357 J. Wildl. Manag. 54, 89-91.

358 Kaufman, L.W., Collier, G., Squibb, R.L., 1978. Selection of an adequate protein / carbohydrate 359 ratio by the domestic chick. Physiol. Behav. 20, 339-344.

360 Kent, J.P.,1987. A note concerning the use of the maternal bond concept. Appl. Anim. Behav. $361 \quad$ Sci. 17, 361-363.

362 Kent, J.P., Murphy, K.J., Bannon, F.J., Hynes, N.M. \& Hayden, T.J. (2009).

363 Testosterone: from initiating change to modulating social organisation in domestic fowl 364 (Gallus gallus domesticus). Naturwissenschaften 96,763-770.

365 Klasing, K.C. (1998). Comparative Avian Nutrition. CAB International. U.K. 
366 Klasing, K.C. (2005). Poultry Nutrition: A comparative approach. J. Appl. Poult. Res. 14: 426$367 \quad 436$

368 Machlis, L., 1977. An analysis of the temporal patterning of pecking in chicks. Behaviour 63, 136970.

370 Miles, F.A., 1972. Centrifugal control of the avian retina. III. Effects of electrical stimulation of 371 the isthmo-optic tract on the receptive field properties of retinal ganglion cells. Brain Res. $372 \quad 48,115-129$.

373 Morris, T.R., Fox S., 1958. Light and sexual maturity in the domestic fowl. Nature 181, 1453-4.

374 Murphy, K.J., 2005, Changes in the peck rate and lateralization of vigilance during feeding, and 375 the endocrinological correlates of social organisation in the developing domestic fowl 376 (Gallus gallus domesticus). PhD thesis, National University of Ireland.

377 Nicol, C.J. (2004). Development, direction and damage limitation: Social learning in domestic 378 fowl. Learn. Behavior, 32, 72-81.

379 Noldus Information Technology, 1993. The Observer. System for collection and analysis of 380 observational data. Version 3.0. Noldus Information Technology, Wageningen, The $381 \quad$ Netherlands.

382 Picard, M., Siegel, P.B., Geraert, P.A., Uzu, G., Williams, P.E.V., 1997. Five genetic stocks of 383 broilers of different growth rate potential choose the same protein: energy balance. In Animal Choices. Br. Soc. Anim. Sci. Occ. Pub. No 20, by J.M. Forbes, T.L.J. Lawrence, R.G. Rodway, \& M.A. Varley, Eds. Br. Soc. Anim. Sci, London, UK. 
386 Rubin, C.J., Zody, M.C., Eriksson, J., Meadows, J.R., Sherwood, E. et al. (2010). Whole-genome resequencing reveals loci under selection during chicken domestication. Nature, 464, 587591.

389 Rugani, R., Kelly, D.M., Sxelest, I., Regolin, L., Vallortigara, G. (2010). Is it only humans that count from left to right? Bio. Lett. doi:10.1098/rsbl.2009.0960

391 Rugani, R., Vallortigara, G., \& Regolin, L. (2014). From small to large: Numerical discrimination by young domestric chicks (Gallus gallus). J. Comp. Psychol. 128, 163-171.

393 Savory, C.J., 1974. The feeding ecology of red grouse in N.E. Scotland. Ph.D. Thesis, University 394 of Aberdeen.

395 Savory, C.J., 1980. Diurnal feeding patterns in domestic fowl: a review. Appl Anim Ethol, 6, 71396 82.

397 Savory, C.J., 1989. The importance of invertebrate food to chicks of gallinaceous species. Proc. $398 \quad$ Nutr. Soc. 48, 113-133.

399 Savory, C.J., Wood-Gush, D.G.M., Duncan, I.J.H., 1978. Feeding behaviour in a population of 400 domestic fowls in the wild. Appl. Anim. Ethol. 4, 13-27.

401 Shariatmadari, F. \& Forbes, J.M. 1993. Growth and food intake response to diets of different 402 protein contents and a choice between diets containing two concentrations of protein in 403 broiler and layer strains of chicken. Brit. Poultry Sci., 34, 959-970.

404 Vallortigara, G., Andrew, R.J., Sertori, L., \& Regolin, L., (1997) Sharply timed behavioral 405 changes during the first 5 weeks of life in the domestic chick (Gallus gallus). Bird Behav., 406 $12,29-40$

407 Workman, L., \& Andrew, R.J. 1989, Simultaneous changes in behaviour and in lateralization 408 during the development of male and female domestic chicks. Anim. Behav. 38, 596-605. 
409 Yo, T., Siegel, P.B., Faure, J.M., Picard, M., 1998. Self-selection of dietary protein and energy by 410 broilers grown under a tropical climate: adaptation when exposed to choice feeding at 411 different ages. Poult. Sci. 77, 502-508.

412 Yo, T., Vilarino, M., Faure, J.M., Picard, M., 1997. Feed pecking in young chickens: new 413 techniques of evaluation. Physiol. Behav. 61, 803-810. 


\section{Table $\mathbf{1}$ (on next page)}

Table 1: Peck rate (per min) for the $1^{\text {st }}$ minute after food presentation; $n=30$ chicks from day 8 (wk 2) to day 65 (wk 10) 


\section{PeerJ Reviewing Manuscript}

Table 1. Peck rate (per min) for the $1^{\text {st }}$ minute after food presentation; $n=30$ chicks from day 8 (wk 2) to day 65 (wk 10)

$\begin{array}{cccccc}\begin{array}{c}\text { Age } \\ \text { (days }\end{array} & \begin{array}{c}\text { Age } \\ \text { (wks) }\end{array} & \begin{array}{c}\text { Peck rate } \\ \text { (pecks/min.) }\end{array} & \text { S.D. } & \text { Range } & \text { N } \\ \text { ) } & & & & & \\ 8 & 2 & 70.86 & 17.05 & 60.38 & 27 \\ 11 & 2 & 73.98 & 19.19 & 70.75 & 30 \\ 14 & 2 & 88.24 & 18.47 & 76.27 & 28 \\ 17 & 3 & 88.62 & 22.86 & 83.33 & 28 \\ 20 & 3 & 99.57 & 21.86 & 86.04 & 30 \\ 23 & 4 & 94.67 & 21.36 & 90.10 & 30 \\ 26 & 4 & 106.44 & 28.62 & 101.85 & 29 \\ 29 & 5 & 111.45 & 26.81 & 112.24 & 30 \\ 32 & 5 & 121.63 & 24.06 & 95.77 & 30 \\ 35 & 5 & 112.46 & 29.76 & 131.65 & 30 \\ 38 & 6 & 119.0 & 30.74 & 124.67 & 30 \\ 41 & 6 & 119.42 & 21.13 & 106.18 & 30 \\ 44 & 7 & 115.58 & 23.70 & 104.28 & 30 \\ 47 & 7 & 99.32 & 32.03 & 132.61 & 30 \\ 50 & 8 & 107.52 & 21.21 & 85.44 & 30 \\ 53 & 8 & 105.57 & 25.24 & 94.9 & 30 \\ 56 & 8 & 95.21 & 20.29 & 75.35 & 30 \\ 59 & 9 & 92.47 & 26.98 & 115.62 & 30 \\ 62 & 9 & 94.31 & 21.23 & 68.22 & 30 \\ 65 & 10 & 93.53 & 29.41 & 139.13 & 30\end{array}$


Table 2 (on next page)

Mean within bout, peck rate after 30 seconds of food crumb pecking, $n=30$ chicks 
Table 2. Mean within bout, peck rate after 30 seconds of food crumb pecking, $n=$ 30 chicks

\begin{tabular}{|cccccc|}
\hline $\begin{array}{c}\text { Age (days) } \\
\text { (wks) }\end{array}$ & 11 & 29 & 41 & 53 & 65 \\
& 2 & 5 & 6 & 8 & 10 \\
$\begin{array}{c}\text { Peck Rate } \\
\text { (pecks/min) } \\
\text { S.D. }\end{array}$ & 151.16 & 170.01 & 201.37 & 178.99 & 166.30 \\
N & 46.25 & 43.99 & 38.58 & 45.76 & 30.78 \\
& 30 & 30 & 30 & 30 & 30 \\
\hline
\end{tabular}




\section{Table 3(on next page)}

Table 3. Pecking at a live mealworm; latency to first peck, latency to swallow, number of pecks to swallow and peck rate; $n=10$ chicks 


\section{PeerJ Reviewing Manuscript}

Table 3. Pecking at a live mealworm; latency to first peck, latency to swallow, number of pecks to swallow and peck rate; $n=10$ chicks

Age (weeks)

Latency to first peck

Mean (sec)

S.D.

Latency to swallow

Mean (sec)

S.D.

No. pecks to swallow

Mean

S.D.

Peck rate

Mean (pecks/min)

S.D.

$\mathrm{N}$

$\begin{array}{cccccccc}5 & 6 & 7 & 8 & 9 & 10 & 11 & 12 \\ & & & & & & & \\ 2.87 & 2.73 & 1.77 & 1.14 & 1.37 & 1.71 & 1.25 & 1.55 \\ 2.73 & 3.61 & 2.04 & .83 & 1.49 & 1.79 & 0.75 & 1.57\end{array}$

3.22

3.08

2.21

1.48

$\begin{array}{ll}1.58 & 2.01\end{array}$

$1.44 \quad 1.80$

2.92

$3.75 \quad 2.57$

.88

$1.58 \quad 1.8$

$0.98 \quad 1.69$

$\begin{array}{llllllll}1.19 & 1.29 & 1.35 & 1.45 & 1.25 & 1.32 & 1.17 & 1.3 \\ .63 & .66 & .69 & .96 & .72 & .48 & .38 & .47\end{array}$

$\begin{array}{llll}65.03 & 63.36 & 77.39 & 84.49\end{array}$

$\begin{array}{llll}80.11 & 69.03 & 70.76 & 80.32\end{array}$

$\begin{array}{llllllll}74.11 & 55.37 & 57.62 & 58.38 & 46.99 & 44.47 & 48.37 & 52.93\end{array}$

99

8

8

9

9

7 
Figure 1

Figure 1: Peck rate (per min.); $n=30$ chicks during the first minute after food presentation every third day from day 8 (wk2) to day 65 (wk 10).

Fig 1: Peck rate (per min.); $\mathbf{n =} \mathbf{3 0}$ chicks during the first minute after food presentation every third day from day 8 (wk2) to day 65 (wk 10). 


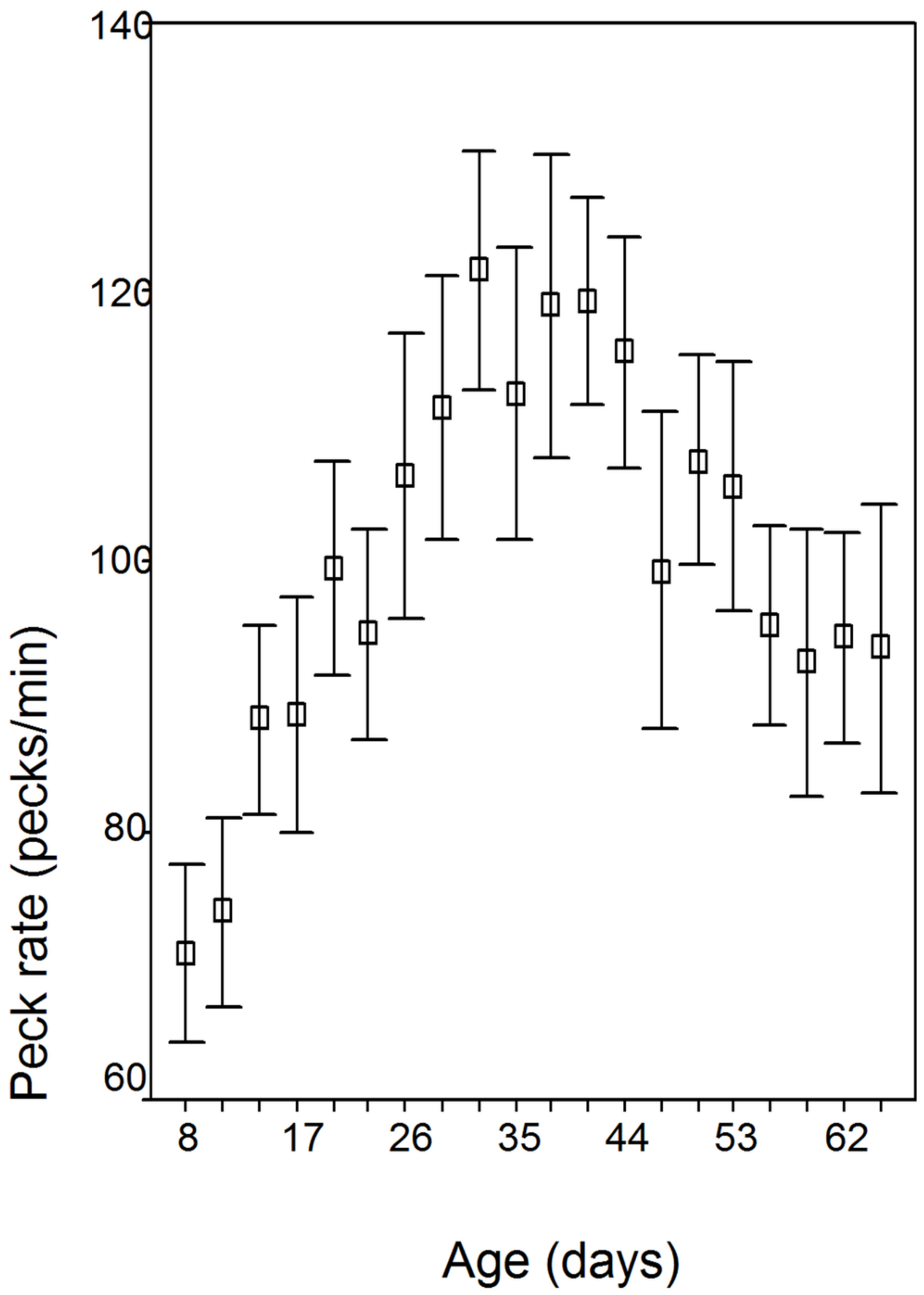


Figure 2

Fig 2: Within bout peck rate (per min.); $n=30$ chicks on five occasions from day 11 (wk2) to 65 (wk10).

Fig 2: Within bout peck rate (per min.); $n=30$ chicks on five occasions from day $11(w k 2)$ to 65 (wk10).

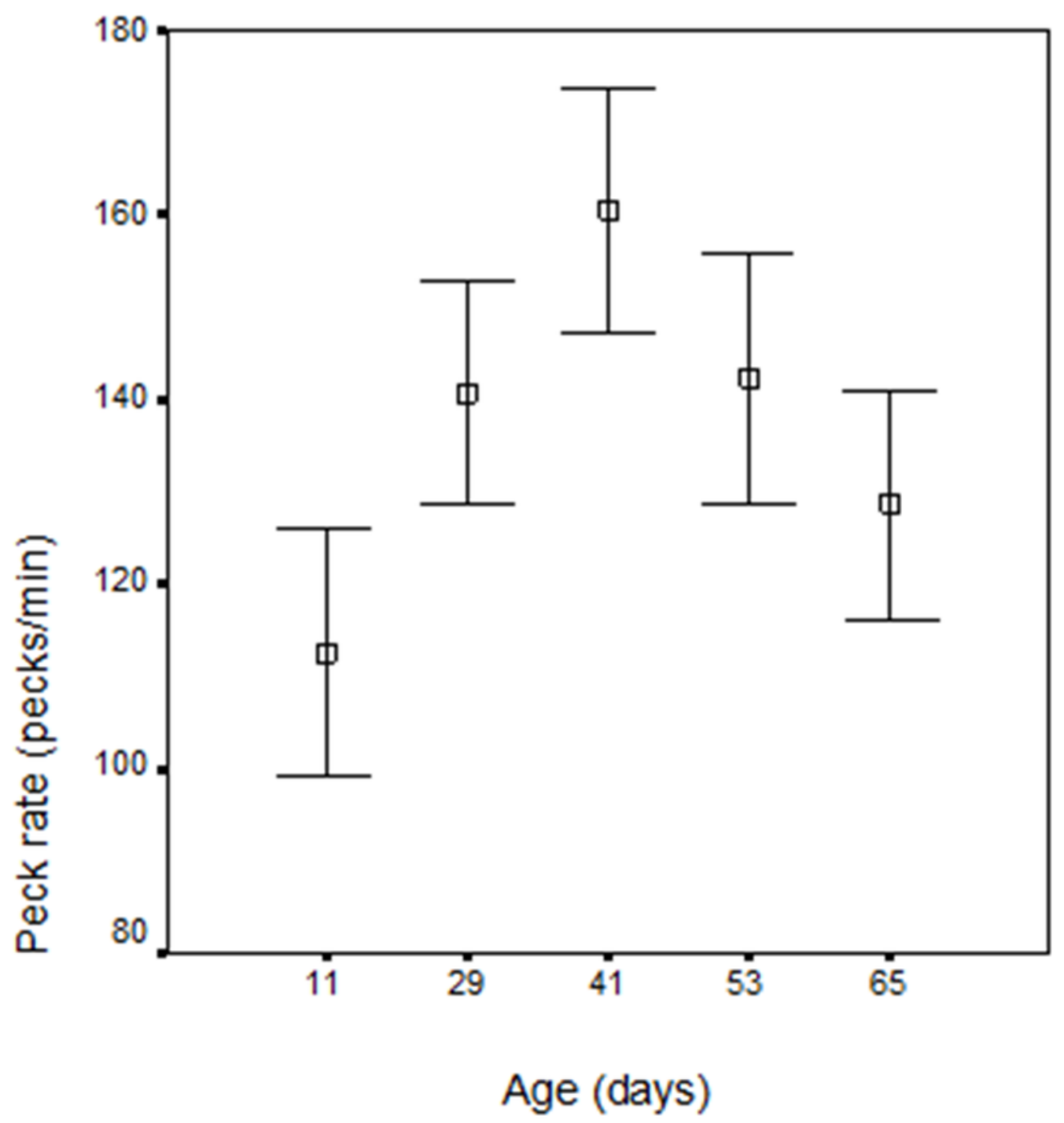

